\title{
Effect of HIP Treatment on Fatigue Notch Sensitivity of Ti-6AI-4V Alloy Fabricated by Electron Beam Melting
}

\author{
Tao Sun ${ }^{1} \cdot$ Yan Liü ${ }^{2,3} \cdot$ Shu-Jun $\mathrm{Li}^{3} \cdot$ Jian-Ping $\mathrm{Li}^{1}$
}

Received: 16 August 2018/Revised: 22 September 2018/Published online: 22 November 2018

(C) The Chinese Society for Metals and Springer-Verlag GmbH Germany, part of Springer Nature 2018

\begin{abstract}
The effect of hot isostatic pressing (HIP) treatment on the fatigue notch sensitivity of Ti-6Al-4V alloy fabricated by electron beam melting (EBM) was investigated. The results indicate that the fatigue notch sensitivity of the as-fabricated samples is much lower than that of HIPed samples. The variation of $\alpha$ lamella thickness and the distribution of pore defects have an effect on the fatigue strength in smooth and notched EBM Ti-6Al-4V samples, resulting in the divergence of the as-fabricated and HIPed samples on fatigue notch sensitivity.
\end{abstract}

Keywords Electron beam melting $\cdot \mathrm{Ti}-6 \mathrm{Al}-4 \mathrm{~V} \cdot$ Fatigue notch sensitivity $\cdot \alpha$ Lamella $\cdot$ Pores

\section{Introduction}

Additive manufacturing via electron beam melting (AMEBM) technology employs a layer-by-layer building process to fabricate $3 \mathrm{D}$, monolithic structures using electron beam as point source heating. The technology is able to build complex shape of a custom-designed component through computer-controlled and selective melting of the associated metal or alloy powder bed. In this process, the particles in the affected layers are completely melted and the as-fabricated products possess strength and elongation comparable to the wrought products [1]. Compared with selective laser melting (SLM), electron beam melting (EBM) is capable of fabricating components with much lower residual stress despite rougher surfaces due to its higher beam energy, and has received great interest in the manufacture of aerospace and medical implants [2-7].

Available online at http://link.springer.com/journal/40195

Tao Sun

suntao@mail.neu.edu.cn

1 State Key Laboratory of Rolling and Automation, Northeastern University, Shenyang 110819, China

2 College of Mechanical Engineering, Shenyang University, Shenyang 110044, China

3 Titanium Alloy Laboratory, Institute of Metal Research, Chinese Academy of Sciences, Shenyang 110016, China
Ti-6Al- $-4 \mathrm{~V}$ is a typical $\alpha+\beta$ dual-phase titanium alloy with excellent comprehensive mechanical properties and good biocompatibility. EBM technique has been applied to fabricate $\mathrm{Ti}-6 \mathrm{Al}-4 \mathrm{~V}$ products for biomedical application. To guarantee the safe application in the human body, it is important that the fabricated products have required mechanical properties. To accomplish these, extensive studies have been performed to establish the processingstructure-properties relationship of EBM Ti-6Al-4V product. For example, the variation of build temperature was found to have a significant effect on the properties and microstructure of the as-deposited samples [8]. Orientations have no influence on ultimate strength (UTS) or yield strength (YS) whereas have large influence on elongation (EL) [9]. Prior- $\beta$ grain size, $\alpha$ lath thickness and mechanical properties, including microhardness, were not found to vary as a function of distance from the build plate [9]. The effect of heat treatment on the unique microstructure formed during the EBM fabrication process has been systematically studied, and the correlation between the variation of $\alpha$ lath thickness and the effect on mechanical properties were established $[10,11]$. The orientation on the fatigue crack propagation (FCG) behavior was studied, and the results indicated that the FCG threshold values were higher for the vertical crack propagation compared to the horizontal crack propagation in the as-fabricated EBM Ti$6 \mathrm{Al}-4 \mathrm{~V}$ extra low interstitial (ELI) alloy [12]. $\beta$ annealing heat treatment results in an increase in fatigue crack growth threshold $\Delta K_{\text {th }}$ compared with the as-fabricated material 
[12]. Hot isostatic pressing (HIP) treatment can coarsen the $\alpha$ plates and eliminate most of pores in EBM samples. Such morphology characteristic can significantly improve the high-cycle fatigue properties [13, 14], leading to a higher fatigue crack propagation rate compared to the as-fabricated samples within certain stress intensity factor range $\left(\Delta K<18 \mathrm{MPa} \mathrm{m}^{1 / 2}\right)[15]$.

In the course of service, the implants will experience the cyclic loading in human body. For the long-term safe application, the EBM implant should possess high fatigue strength. Till now, extensive studies have been done to explore the fatigue behavior of AM Ti-6Al-4V alloys. Most of them focused on the high-cycle fatigue and fatigue crack propagation behaviors [13-19]. It is known that the insensitivity of orthopedic implants to notches can prevent sudden expansion of the existing notches in the implants and provide time for the patients' self-examination and doctors' treatment. Thus, it is also important to evaluate the fatigue notch sensitivity of EBM products for their safe application in human body. Several studies have investigated the effect of as-built surface condition and the geometrical notch on the fatigue notch sensitivity [20-22]. Most of them focus on SLM products. Since the morphology and mechanical properties of EBM Ti-6Al-4V alloy are quite different from those of SLM alloy [14], their fatigue notch sensitivity may be quite different. However, few related results have been reported. In this work, the Ti$6 \mathrm{Al}-4 \mathrm{~V}$ samples were prepared using EBM technique and the effect of HIP treatment on the fatigue notch sensitivity of the EBM Ti-6Al-4V alloy was investigated and the underlying mechanism was discussed.

\section{Experimental}

Ti-6Al-4V cylinders were fabricated by an EBM system manufactured by Arcam, Sweden (Arcam A1). These parts were built layer by layer using the precursor Ti-6Al-4V powder with average diameter $\sim 50 \mu \mathrm{m}$ (Fig. 1). Each powder layer was created by raking powder gravity fed from two cassettes, heated to $\sim 730{ }^{\circ} \mathrm{C}$ by multiple preheat scans and then melted the selected layer areas driven by a three-dimensional CAD program. The chemical composition of Ti-6Al-4V alloy powder used in this work is shown in Table 1 .

The cylinders with diameter of $12 \mathrm{~mm}$ were directly built on the start plate. The building direction of the samples was perpendicular to the start plate. Some of EBM samples were HIP-treated in a QIH-15 hot isostatic pressing furnace at $930{ }^{\circ} \mathrm{C}$ with pressure of $130 \mathrm{MPa}$ for $3 \mathrm{~h}(18$ $\mathrm{ks}$ ), and then, furnace is being cooled down to room temperature. Then, these as-fabricated and HIPed cylinders were machined to V-type circumferential notch samples

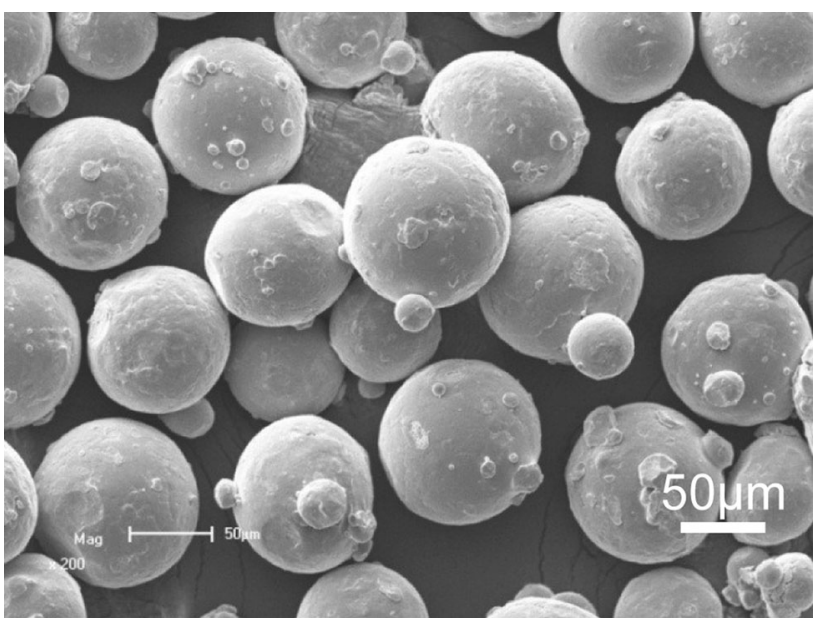

Fig. 1 Morphology of Ti-6Al-4V ELI alloy powder

(see the details in Fig. 2) with stress concentration factor $\left(K_{\mathrm{t}}\right)$ of 3. Constant stress amplitude fatigue tests were performed on Instron-8872 fatigue testing system at stress ratios $R$ of 0.1 at room temperature. Load configuration with sinusoidal waveform and frequency $f=20 \mathrm{~Hz}$ was used. All samples were polished mechanically in order to reduce the surface roughness before test. Fatigue limit was determined as the maximum stress below which fatigue failure did not occur after $10^{7}$ cycles. To guarantee the accuracy, the fatigue limit was confirmed by the repeated tests of two samples.

The microstructures were observed by a ZEISS-AXIO optical microscopy (OM) and a JSM-6301F scanning electron microscope (SEM). The samples for the OM and SEM analysis were mechanically polished and then etched in a solution consisting of $2 \mathrm{vol} \% \mathrm{HF}, 5 \mathrm{vol} \% \mathrm{HNO}_{3}$ and $43 \mathrm{vol} \% \mathrm{H}_{2} \mathrm{O}$. Phase constitutions were examined on an $\mathrm{X}$-ray diffractometer (XRD) using a $\mathrm{Cu} K_{\alpha}$ radiation source with an accelerating voltage of $40 \mathrm{kV}$ and a current of $250 \mathrm{~mA}$. The fracture surfaces of samples were observed by SEM. Before observation, the fracture surfaces of samples were cleaned by alcohol. The samples were carried out micro-CT scan using a Zeiss Versa 500 Micro-CT system in order to find the distribution of pores in EBM samples. The micro-CT was performed using at an accelerating voltage of $160 \mathrm{kV}$ and current of $62.5 \mu \mathrm{A}$. The micro-CT 3D data were analyzed by Avizo 8.0 software.

\section{Results}

\subsection{Microstructure and Phase Composition}

Figure 3 shows the optical micrographs of as-fabricated and HIPed EBM samples. It can be seen that the as-fabricated EBM samples mainly consist of $\alpha$ phase. The TEM 
Table 1 Chemical compositions of $\mathrm{Ti}-6 \mathrm{Al}-4 \mathrm{~V}$ alloy powder used in this study

\begin{tabular}{lllllllll}
\hline Sample & Al & V & Ti & Fe & C & N & H & O \\
\hline GB/T3620.1-1994 & $5.50-6.80$ & $3.50-4.50$ & Bal. & 0.300 & 0.100 & 0.050 & 0.015 & 0.20 \\
EBM powder & 6.04 & 4.05 & Bal. & 0.070 & 0.013 & $<0.005$ & $<0.005$ & 0.13 \\
\hline
\end{tabular}

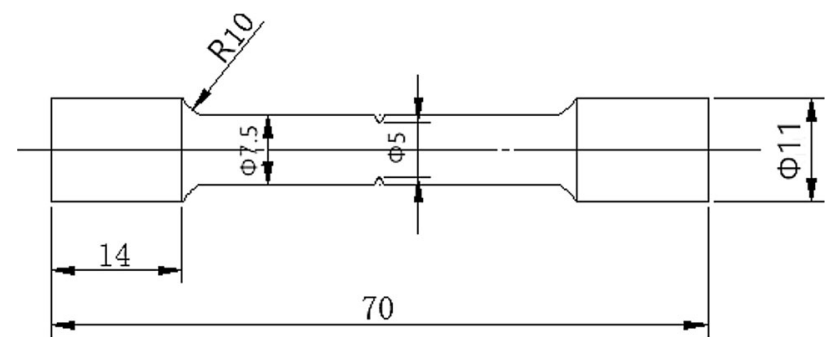

Fig. 2 Geometry and dimension of fatigue notch sample of Ti-6Al$4 \mathrm{~V}$ fabricated by EBM

analyses found a small amount of thin $\beta$ phase surrounded by the coarser $\alpha$ lamellar (Fig. 4a). Selected area electron diffraction (SAED) pattern from $[001]_{\alpha}$ taken from regions containing $\alpha+\beta$ phase is shown in Fig. 4c. The orientation relationship between the $\alpha$ phase and the $\beta$ phase can be determined as $[110]_{\beta} / /[001]_{\alpha}$, which obeys the Burgers orientation relationship. After HIP treatment, the thickness of $\alpha$ plates significantly increased. The coarsened $\alpha$ lamella after HIP treatment is attributed to the high heat treatment temperature $(1203 \mathrm{~K})$ which is close to $\beta$ transus temperature $(1253 \pm 10 \mathrm{~K})$ and the subsequent slow cooling (furnace cooling). The width of $\alpha$ lamella is diffusion controlled and accelerated by high temperature and relatively long cooling time.

\subsection{Defects}

Figure 5 indicates a large amount of pores in the as-fabricated EBM samples. Most of the pores in the EBM samples have average size about $39 \mu \mathrm{m}$. Previous studies indicated that the pores were the main defects in EBM samples [15]. The formation of these pores may be due to the two followed reasons: One is defects included in the powders [23], and the other is the material vaporization [24]. After HIP treatment, most of the pores were closed due to the high temperature and pressure. The samples have been significantly densified.
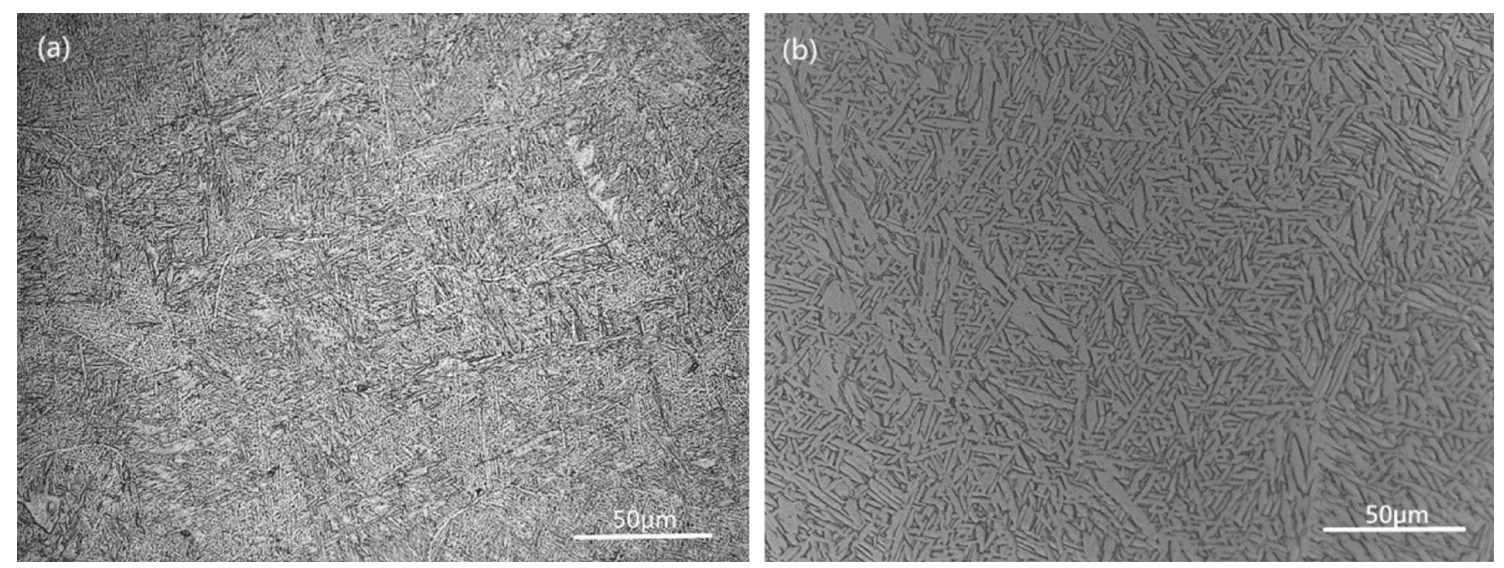

Fig. 3 Optical microstructures of as-fabricated a, HIPed b Ti-6Al-4V samples fabricated by electron beam melting
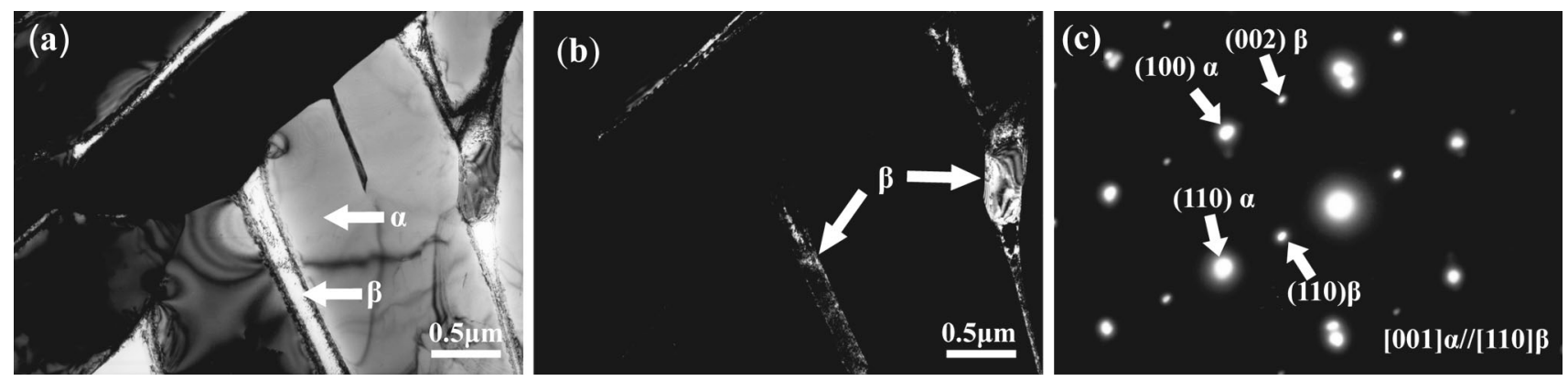

Fig. 4 TEM bright-field images a, dark-field images $\mathbf{b}$, SAED pattern $\mathbf{c}$ of as-fabricated EBM Ti-6Al-4V 

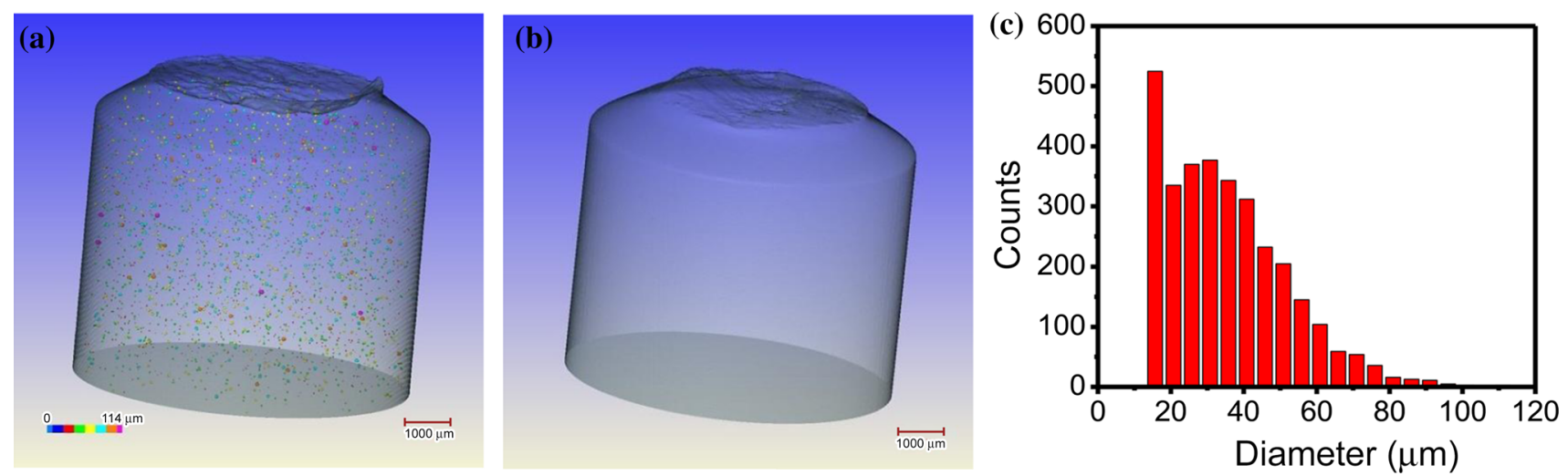

Fig. 5 Micro-CT results of as-fabricated $\mathbf{a}$, HIPed $\mathbf{b}$ samples fabricated by EBM, pore distribution of as-fabricated sample $\mathbf{c}$

\subsection{Mechanical Properties}

The tensile properties of the studied EBM Ti-6Al-4V samples at room temperature are shown in Table 2. The results indicate that the HIP treatment leads to the decrease in the strength and increase in ductility. The variation of the mechanical properties is mainly due to the change of thickness of $\alpha$ lamella. It has been reported that the relation of strength $\sigma_{y s}$ and thickness of $\alpha$ lamella for two phases titanium alloy can be estimated from the Hall-Petch equation $[25,26]$ :

$\sigma_{y s}=\sigma_{0}+K_{y} d^{-1 / 2}$,

where $\sigma_{0}$ is the yield strength of single crystal, $K_{y}$ is the strengthening coefficient and $d$ is the average grain diameter or average layer thickness. From the equation, it is seen that the strength of two-phase titanium alloy varies inversely with thickness of $\alpha$ lamella. The above results indicated that the $\alpha$ lamella significantly coarsened by HIP treatment, so it is easy to deduce the decrease in strength with annealing temperature.

\subsection{Fatigue Notch Sensitivity}

Fatigue tests were conducted on both the smooth and notched samples of the as-fabricated and HIPed Ti-6Al$4 \mathrm{~V}$ alloy prepared by the EBM method. It can be seen from Figs. 6 and 7 that the fatigue strength of the HIPed smooth sample $(\sim 550 \mathrm{MPa})$ is higher than that of the as-

Table 2 Tensile properties of EBM Ti-6Al-4V alloy

\begin{tabular}{lccll}
\hline Material & UTS (MPa) & YS (MPa) & EL $(\%)$ & RA (\%) \\
\hline As-fabricated & $1036 \pm 5$ & $955 \pm 3$ & $14.7 \pm 0.6$ & $42.6 \pm 0.2$ \\
HIPed & $979 \pm 2$ & $887 \pm 5$ & $16.7 \pm 0.5$ & $51.7 \pm 0.1$
\end{tabular}

UTS ultimate tensile strength, YS yield strength, EL elongation, $R A$ reduction in area fabricated smooth sample $(\sim 450 \mathrm{MPa})$, whereas the asHIPed notched sample $(\sim 300 \mathrm{MPa})$ is lower than that of the as-fabricated notched sample $(\sim 350 \mathrm{MPa})$.

In general, the fatigue notch sensitivity $q$ is calculated by the following formula [27]:

$q=\frac{K_{\mathrm{f}}-1}{K_{t}-1}$,

where $K_{t}$ is the stress concentration factor and $K_{\mathrm{f}}$ is the fatigue notch factor and is defined as:

$K_{\mathrm{f}}=\frac{\sigma_{\mathrm{c}, \text { smooth }}}{\sigma_{\mathrm{c}, \text { notch }}}$,

where $\sigma_{\mathrm{c}, \text { smooth }}$ and $\sigma_{\mathrm{c} \text {,notch }}$ are the fatigue strengths of the smooth samples and notched samples, respectively. $K_{t}$ depends on notch geometry of samples and property of materials. Value of $q$ is related to the property of materials, indicating whether a material is sensitive to notch or not. During fatigue process, it can reflect the stress redistribution near notch root and the capacity to resist stress concentration in materials.

Table 3 shows the fatigue notch sensitivities of the asfabricated and HIPed samples calculated by Eq. (2), which

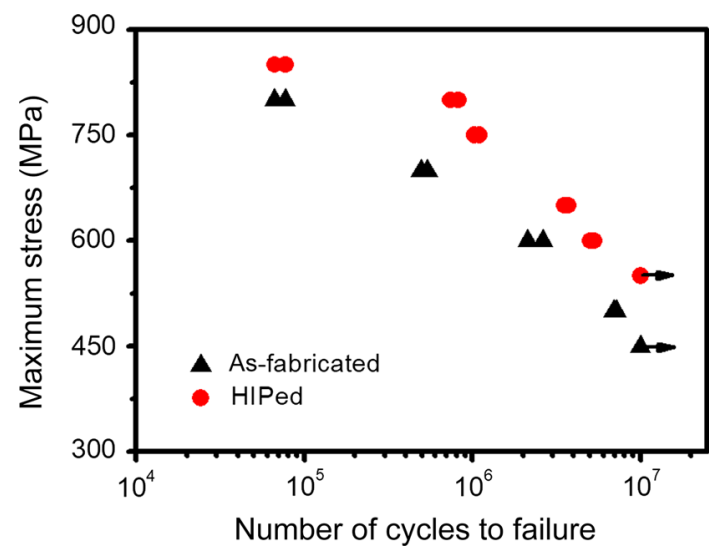

Fig. 6 Maximum stress-number of cycles to failure $(S-N)$ curves of as-fabricated and HIPed smooth EBM Ti-6Al-4V samples 


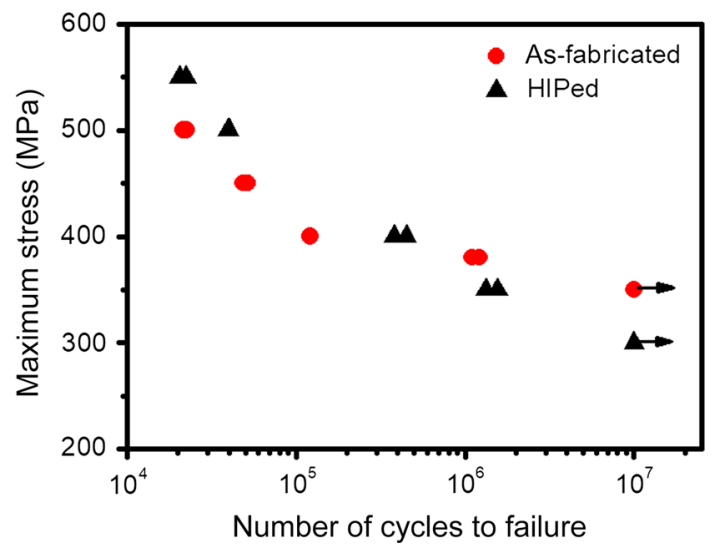

Fig. $7 S-N$ curves of as-fabricated and HIPed notched EBM Ti-6Al$4 \mathrm{~V}$ samples

shows that the fatigue notch sensitivity of the as-fabricated sample $(\sim 0.14)$ is much lower than that of HIPed sample ( $\sim 0.42)$, which indicates that HIPed samples seem to be more sensitive to the notch. It should be mentioned that the number of the samples used for the fatigue limit test does not totally meet the staircase method. As such, the fatigue limit of the studied samples should be further accurately examined prior to engineering application.

\section{Discussion}

The above results show that the notch sensitivity of the asfabricated EBM samples is far lower than that of the HIPed ones. Since HIP treatment may result in the closure of the pore defects and the coarsening of $\alpha$ lamella in the EBM samples, the differences between the as-fabricated and HIPed samples in terms of notch sensitivity are explained through analyzing the contributions of these two factors to fatigue strength of the smooth and notched samples.

\subsection{Effect of Pore Defects}

The high-cycle fatigue life of metallic materials refers chiefly to its fatigue crack initiation and propagation life, while the former predominates the high-cycle fatigue life for the smooth samples [28]. In preparing Ti-6Al-4V alloy samples using the EBM method, pore defects are inevitable. Cracks are easier to initiate near the defects and deteriorate the fatigue strength of the as-fabricated EBM samples [29]. HIP treatment can eliminate these pore defects, thus prolonging the crack initiation life of the materials [30, 31]. For the smooth samples, therefore, the fatigue strength of HIPed samples is superior to the asfabricated ones.

For the notch samples, since stress concentrates on the root of the notch, the cracks initiate at the sample surface near the notch (not near pore defect) for either the asfabricated or the HIPed samples (as shown in Fig. 8a and b). Furthermore, as the effect of pore defects on crack initiation is weakened, the strength of the samples becomes the key factor that determines the crack initiation life [32]. Compared with the as-fabricated samples, the HIPed samples have a lower strength, and thus, the as-fabricated notch samples are superior to the HIPed samples in resisting crack initiation. In addition, during the crack propagation stage, the pore defects in the as-fabricated notch samples may cause the main crack to propagate in different directions, and even lead to the secondary crack initiation near the main crack (as shown in Fig. 8c), and thus, the crack propagation life is prolonged through reducing the energy along the main crack and lowering the propagation speed [10]. After HIP treatment, however, the pores are closed, so no secondary crack appears along the main crack (as shown in Fig. 8d), and the crack just propagates along the main crack direction, and it is deduced that its crack propagation life is lower than the asfabricated ones. The above analyses reveal that pores have no adverse effect on the crack initiation, but contribute to the longer crack propagation life of the as-fabricated notch samples. Thus, the fatigue strength of the as-fabricated notch samples is higher than that of the HIPed notch samples.

\subsection{Effect of $\alpha$ Lamella Thickness}

After HIP treatment, the $\alpha$ lamella in the EBM samples becomes thicker, which leads to a lower tensile strength of the HIP samples and further weakens the resistance to crack initiation of the notch samples on one hand; on the other hand, an increase in $\alpha$ lamella thickness makes the

Table 3 Fatigue notch sensitivities of EBM Ti-6Al-4V samples in different conditions

\begin{tabular}{llll}
\hline & Fatigue strength of smooth sample (MPa) & Fatigue strength of notched sample (MPa) & Fatigue notch sensitivity \\
\hline As-fabricated & 450 & 350 & 0.14 \\
HIPed & 550 & 300 & 0.42 \\
Wrought [33] & 550 & 280 & 0.48 \\
\hline
\end{tabular}



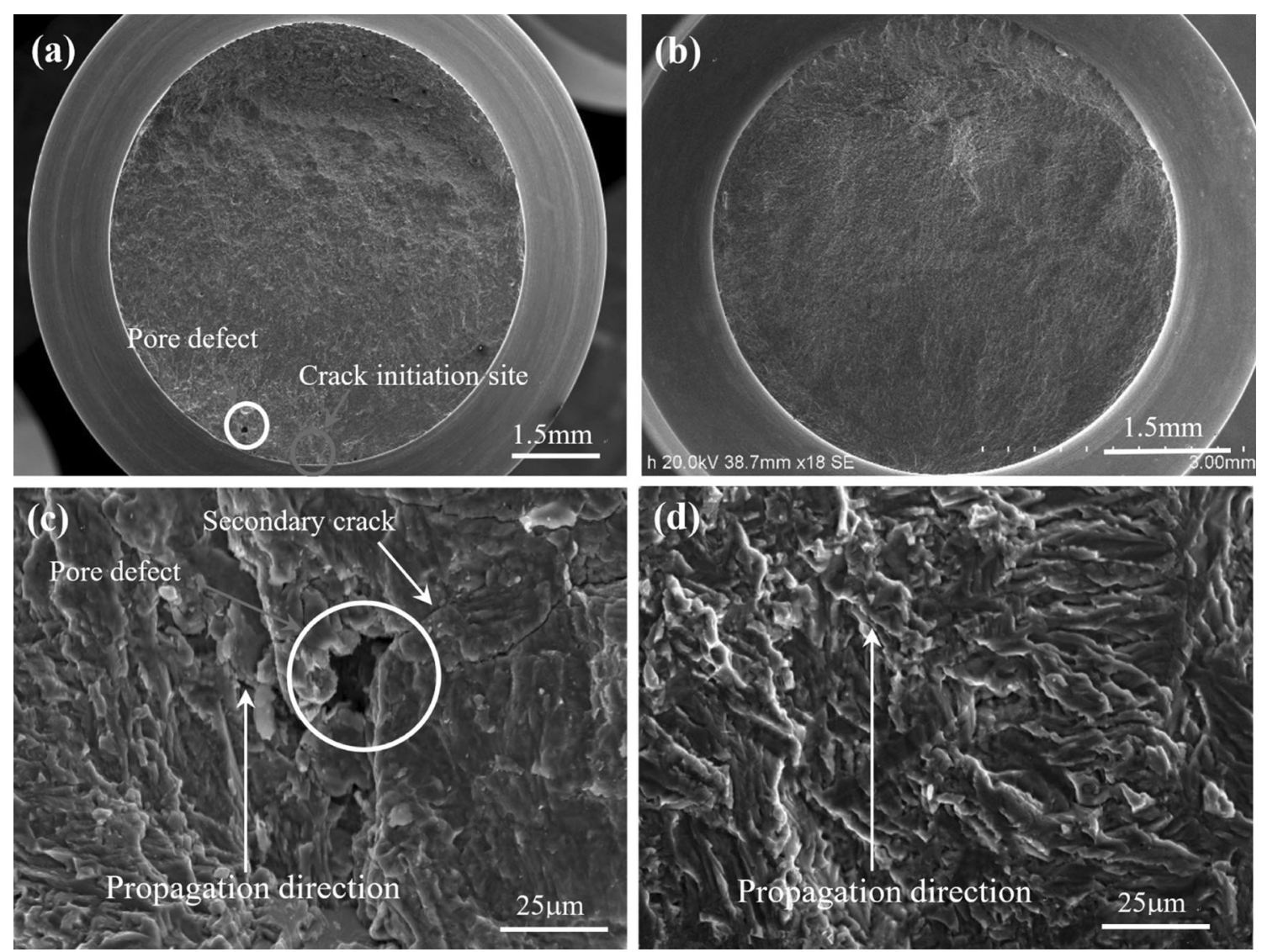

Fig. 8 SEM images of fracture surfaces of as-fabricated a, $\mathbf{c}$; HIPed $\mathbf{b}, \mathbf{d}$ EBM Ti-6Al-4V samples at low a, b; high $\mathbf{c}, \mathbf{d}$ magnification

crack in the notch samples to pass through less $\alpha$ lamella during propagation, and accordingly, the propagation path deflects less, leading to a faster crack propagation speed [15]. Compared with the as-fabricated notch samples, therefore, HIPed notch samples have lower fatigue strength.

In a word, for the as-fabricated sample, the existence of the pores may lead to lower fatigue strength but has no adverse effect on the fatigue strength. For the HIPed samples, the disappearing of the pores may lead to higher fatigue strength; however, the thickening of $\alpha$ lamella may lead to lower notch strength. Based on Eq. (2), it is concluded that the notch sensitivity of the as-fabricated samples is far lower than HIPed samples.

Fatigue notch sensitivities of the studied EBM Ti-6Al$4 \mathrm{~V}$ alloy were also compared with the results from the reported wrought alloys with identical mechanical properties (Table 3). It is clear that the HIPed samples show comparable fatigue notch sensitivities as the wrought alloys, despite a lower value for the as-fabricated samples. Based on the above analysis, the lower fatigue notch sensitivity may be due to the fine lamella and the pores contained in the as-fabricated samples.

\section{Conclusions}

1. The fatigue notch sensitivity of as-fabricated EBM Ti$6 \mathrm{Al}-4 \mathrm{~V}$ sample $(\sim 0.14)$ is much lower than that of HIPed sample $(\sim 0.42)$, indicating higher notch sensitivity of the HIPed samples.

2. The variation of $\alpha$ lamella thickness and the pore defects distribution have an effect on the fatigue strength of the smooth and notched Ti-6Al-4V alloys fabricated by the EBM technique, and result in the difference of fatigue notch sensitivity of the asfabricated and HIPed samples.

Acknowledgements This work was supported financially by the National Natural Science Foundation of China (No. 51274063) and the Fundamental Research Funds for the Central Universities (No. N170704015).

\section{References}

[1] L.E. Murr, E.V. Esquivel, S.A. Quinones, S.M. Gaytan, M.I. Lopez, E.Y. Martinez, F. Medina, D.H. Hernandez, E. Martinez, J.L. Martinez, S.W. Stafford, D.K. Brown, T. Hoppe, W. Meyers, U. Lindhe, R.B. Wicker, Mater. Charact. 60, 96 (2009) 
[2] L.E. Murr, S.A. Quiones, S.M. Gaytan, M.I. Lopez, A. Rodela, E.Y. Martinez, D.H. Hernandez, E. Martinez, F. Medina, R.B. Wicker, J. Mech. Behav. Biomed. Mater. 2, 20 (2009)

[3] B. Bachy, R. Süß-Wolf, L. Wang, Z.W. Fu, N. Travitzky, P. Greil, J. Franke, Adv. Eng. Mater. 20, 1700842 (2018)

[4] Y.J. Liu, H.L. Wang, S.J. Li, S.G. Wang, W.J. Wang, W.T. Hou, Y.L. Hao, R. Yang, L.C. Zhang, Acta Mater. 126, 58 (2017)

[5] Y.J. Liu, S.J. Li, H.L. Wang, W.T. Hou, Y.L. Hao, R. Yang, T.B. Sercombe, L.C. Zhang, Acta Mater. 113, 56 (2016)

[6] L.Z. Wang, W.H. Wei, Acta Metall. Sin. (Engl. Lett.) 31, 807 (2018)

[7] Y.L. Guo, L.N. Jia, B. Kong, Y.L. Huang, H. Zhang, Acta Metall. Sin. (Engl. Lett.) 31, 477 (2018)

[8] S.S. Al-Bermani, M.L. Blackmore, W. Zhang, I. Todd, Metall. Mater. Trans. A 41, 3422 (2010)

[9] N. Hrabe, T. Quinn, Mater. Sci. Eng. A 573, 264 (2013)

[10] H.Z. Galarraga, R.J. Warren, D.A. Lados, R.R. Dehoff, M.M. Kirka, P.Y. Nandwana, Mater. Sci. Eng. A 685, 417 (2017)

[11] C. Formanoir, S. Michotte, O. Rigo, L. Germain, S. Godet, Mater. Sci. Eng. A 652, 105 (2016)

[12] H. Galarraga, R.J. Warren, D.A. Lados, R.R. Dehoff, M.M. Kirka, Eng. Fract. Mech. 176, 263 (2017)

[13] X.L. Shui, K. Yamanaka, M. Mori, Y. Nagata, K. Kurita, A. Chiba, Mater. Sci. Eng. A 680, 239 (2017)

[14] X.L. Zhao, S.J. Li, M. Zhang, Y.D. Liu, T.B. Sercombe, S.G. Wang, Y.L. Hao, R. Yang, L.E. Murr, Mater. Des. 95, 21 (2016)

[15] Y. Liu, J. Zhang, S.J. Li, W.T. Hou, H. Wang, Q.S. Xu, Y.L. Hao, R. Yang, Acta Metall. Sin. (Engl. Lett.) 30, 1163 (2017)

[16] N. Hrabe, T. Gnäupel-Herold, T. Quinn, Int. J. Fatigue 94, 202 (2017)
[17] H.J. Gong, K. Rafib, H.F. Gu, G.D. Janaki Ram, T. Starr, B. Stucker, Mater. Des. 86, 545 (2015)

[18] D. Greitemeier, F. Palm, F. Syassen, T. Melz, Int. J. Fatigue 94, 211 (2017)

[19] B.V. Hooreweder, D. Moens, R. Boonen, J.P. Kruth, P. Sas, Adv. Eng. Mater. 14, 92 (2012)

[20] G. Nicoletto, Int. J. Fatigue 106, 124 (2018)

[21] G. Nicoletto, R. Konecna, L. Kunz, M. Frkan, in MATEC Web Conference, vol. 165, p. 02002 (2018)

[22] M. Kahlin, H. Ansell, J.J. Moverare, Int. J. Fatigue 103, 353 (2017)

[23] S.M. Gaytan, L.E. Murr, F. Medina, E. Martinez, M.I. Lopez, R.B. Wicker, Mater. Technol. 24, 180 (2009)

[24] D. Dai, D. Gu, Appl. Surf. Sci. 355, 310 (2015)

[25] C. Leyens, M. Peters, Z. Chen, Titanium and Titanium Alloys (Chemical Industry Press, Beijing, 2005)

[26] H. Shi, X. Ren, Mechanical Properties of Materials (Peking University Press, Beijing, 2010)

[27] A. Mehryab, H. Arabi, M. Tamizifar, S.H. Seyedein, M.A. Razazi, Iran. J. Mater. Sci. Eng. 2, 9 (2005)

[28] S. Suresh, Fatigue of Materials (Cambridge University Press, New York, 1998)

[29] P. Edwards, M. Ramulu, Mater. Sci. Eng. A 598, 327 (2014)

[30] S. Lenders, M. Thoene, A. Riemer, T. Niendorf, T. Troester, H.A. Richard, H.J. Maier, Int. J. Fatigue 48, 300 (2013)

[31] V. Cain, L. Thijs, J.V. Humbeeck, B.V. Hooreweder, R. Knutsen, Addit. Manuf. 5, 68 (2015)

[32] S.J. Li, T.C. Cui, Y.L. Hao, R. Yang, Acta Biomater. 4, 305 (2008)

[33] J.R. Zhang, S.A.A. Shah, Y.L. Hao, S.J. Li, R. Yang, Sci. China Mater. 4, 537 (2018) 